\title{
APRESENTAÇÃO DO MODELO MATEMÁTICO PARA O PROBLEMA DE ROTEIRIZAÇÃO DE VEÍCULOS COM JANELAS DE TEMPO
}

\author{
Dayse da Silva Pacifico \\ Instituto Militar de Engenharia \\ Praça Gen. Tibúrcio, 80 - Urca, Rio de Janeiro - RJ \\ daysespacifico@gmail.com \\ Orivalde Soares da Silva Júnior \\ Instituto Militar de Engenharia \\ Praça Gen. Tibúrcio, 80 - Urca, Rio de Janeiro - RJ \\ orivalde@yahoo.com.br
}

\begin{abstract}
RESUMO
Neste trabalho é realizada uma revisão bibliográfica acerca problema de roteirização de veículos com janelas de tempo. Este problema é uma especialização do problema tradicional de roteirização, pois apresenta restrições de janelas de tempo. Portanto, o objetivo do trabalho é aplicar o conhecimento da pesquisa operacional e apresentar o modelo matemático de um problema de roteirização com restrições de janela de tempo.
\end{abstract}

Palavras-chave: roteirização de veículos; janelas de tempo; logística.

\begin{abstract}
In this work, a bibliographic review about open routing problem with time window vehicles is performed. The presentation of the problem is a specialization of the traditional scripting problem, as it has a restriction on the travel time window. Therefore, the objective of this paper is to apply the knowledge of operational research and to present the mathematical model of a time window constrained routing problem.
\end{abstract}

Keywords: vehicle routing; time windows; logistics.

\section{Como Citar:}

PACIFICO, Dayse da Silva; SILVA JÚNIOR, Orivalde Soares da. APRESENTAÇÃO DO MODELO MATEMÁTICO PARA O PROBLEMA DE ROTEIRIZAÇÃO DE VEÍCULOS COM JANELAS DE TEMPO. In: SIMPÓSIO DE PESQUISA OPERACIONAL E LOGÍSTICA DA MARINHA, 19. 2019, Rio de Janeiro, RJ. Anais [...]. Rio de Janeiro: Centro de Análises de Sistemas Navais, 2019.

\section{INTRODUÇÃO}

A globalização trouxe acirramento da concorrência e a necessidade das empresas estabelecerem novas estratégias para garantir sua sobrevivência em um mercado cada vez mais competitivo. Isso tem exigido das empresas decisões mais rápidas e precisas em relação aos negócios. Neste novo cenário, o foco é tornar as empresas mais dinâmicas e menos complexas em relação a processos administrativos e operacionais. Desta forma a logística ganha destaque, pois desempenha papel fundamental para a sobrevivência das organizações. 
A gestão da cadeia de suprimentos (GCS) pode se transformar em uma significativa vantagem em relação aos seus concorrentes, em termos de preferência dos clientes, e ser considerado um diferencial competitivo importante em mercados cada vez mais abrangentes.

Ching (2010) descreve que para aquisição de vantagem competitiva por parte das empresas, com base em fatores como diferenciação do produto, aumento de produtividade e níveis de serviço a seus clientes, os processos não devem se limitar apenas aos limites internos da empresa, estendendo-os a todas as partes envolvidas também externamente, ou seja, fora dos limites da empresa. Esta visão da cadeia como um todo, também chamada enfoque sistêmico, caracteriza um dos pilares do SCM.

A alta complexidade gerencial, a intensa utilização de ativos e a gestão sob um grande fluxo físico de produtos tornam o transporte como sendo a atividade que possui maior percencial dos custos logísticos, e que pode variar de um terço (produtos de alto valor agregado) a dois terços (produtos de baixo valor agregado) do total dos custos logísticos das empresas.

Várias companhias cada vez mais contratam serviços de transporte terceirizados para realizar a entrega de seus produtos para os seus clientes. Isso acontece pois, por meio da contratação de frotas de veículos de entrega, é possível obter uma significativa redução em gastos referentes aos serviços de transporte.

Para Repoussis et al. (2006), essa contratação se justifica mesmo em casos em que o custo do aluguel de frotas de veículos seja mais caro pela distância percorrida, devido à economia com a manutenção da frota, por exemplo, dentre outros gastos.

A pesquisa operacional, nos últimos tempos, tem desenvolvido uma grande variedade de modelos e algoritmos de otimização para a resolução de problemas em diversas áreas. As ferramentas de apoio à decisão se fundamentam fortemente nas técnicas de otimização, entretanto, sua aplicação prática pode acarretar diversas dificuldades na fase de modelagem e no gerenciamento eficiente dos sistemas computacionais caso não seja realizada de forma correta.

A roteirização é uma importante ferramenta para a redução dos custos e aumento da eficiência operacional, mas depende de alguns fatores essenciais, entre eles uma base de dados atualizada e sistemas modernos, normalmente baseados em Sistema de Informações Geográficas. O objetivo geralmente é minimizar os custos totais de transporte. Muitas vezes, é uma combinação de custos de aquisição/depreciação de frota e custos de condução para o plano de roteirização.

Pela conceituação de Rago (2002), roteirização de carga é o processo de programação da distribuição da carga em rotas ou roteiros de entrega, realizando o cruzamento de informações de volume/peso da carga, capacidades dos veículos e locais de entrega, a fim de obter o melhor resultado em termos de ocupação dos caminhões e cumprimento dos prazos de entrega.

Para Brandão (2004), o Problema de Roteirização de Veículos (PRV) consiste em definir as melhores rotas para uma frota de veículos, considerando a janela de tempo que o cliente está disponível para receber os produtos ou serviços (PRVJT). Quando o tempo de chegada de um veículo $k$ em um cliente $i$ é menor do que o início da janela de tempo $a_{i}$, este veículo deve aguardar um tempo de espera. $\mathrm{O}$ veículo não pode chegar após o término da janela de tempo do cliente $b_{i}$.

O problema matemático do PRVJT proposto por Kloster (2007) pode ser formulado de modo que se tenha um conjunto $V$ de vértices, sendo $V=\{0,1,2, \ldots, N\}$. Assim como no PRV, o PRVJT tem como objetivo criar uma solução em que sejam minimizados o número de veículos utilizados e a distância total percorrida por eles, mas respeitando as restrições referentes às janelas de tempo associadas aos clientes a serem atendidos. 
O número de locais existentes é igual a $\mathrm{N}$, ou seja, os clientes e o depósito, sendo o índice do depósito igual a 0 . Cada aresta (i,j) possui umuma distância $d_{i j}$ associada. $\mathrm{O}$ valor do custo $c_{i j}$ e do tempo de viagem $t_{i j}$ entre dois clientes $i$ e $j$ é equivalente a $d_{i j}$. As variáveis de decisão $x_{i j k}$ tem como finalidade definir se um cliente $i$ precede um cliente $j$ atendido por um veículo $k$, em que ela recebe o valor 1 se o cliente $i$ precede $j$ e 0 caso contrário. As variáveis de decisão $s_{i}^{k}$ indicam o horário de início exato do serviço em cada cliente e no depósito. A capacidade de cada veículo é igual a $q$. A demanda de cada cliente $i$ é definida pelo parâmetro $d_{i}$. Além disso, assumimos que $t_{i j}$ inclui a duração do serviço no cliente $i$. $\mathrm{O}$ modelo matemático de programação linear é apresentado a seguir.

$$
\begin{aligned}
& \text { Minimizar } z=\sum_{k \in V} \sum_{(i, j) \in A} c_{i j} x_{i j}^{k} \\
& \sum_{k \in V}^{\text {S.a. }} \sum_{j \in N} x_{i j}^{k}=1 \forall{ }_{i} \in C \\
& \sum_{(i, j) \in A} d_{i} x_{i j}^{k} \leq q \forall k \in V \\
& \sum_{j \in N i 0\} x_{0 j}^{k}=1 \forall} \quad \vdots \\
& \sum_{i \in N} x_{i h}^{k}-\sum_{j \in N} x_{h j}^{k}=0, \forall h \in C, k \in V \\
& \sum_{i \in N}^{k} x_{i, n+1}^{k}=1 \forall k \in V \\
& x_{i j}^{k}\left(s_{i}^{k}+t_{i j}-s_{j}^{k}\right) \leq 0, \forall(i, j) \in A, k \in V \\
& a_{i} \leq s_{i}^{k} \leq b_{i}, \forall i \in N, k \in V \\
& x_{i j}^{k} \in\{0,1\} \forall(i, j) \in A, k \in V \\
& s_{i}^{k} \geq 0 \forall i \in N, k \in V
\end{aligned}
$$

A função objetivo (1) busca minimizar a soma dos custos de viagem em todos os arcos usados na solução. As restrições (2) expressam que todos os clientes devem ser atendidos exatamente uma vez. As restrições visam (3) garantir que nenhuma rota viole as restrições de capacidade do veículo. Já as restrições (4) dizem que há exatamente uma rota por veículo. As restrições (5) visam garantir que, se um determinado veículo chegar a um cliente, ele também saia desse cliente. As restrições (6) dizem que todos as rotas terminam no depósito. As restrições de janela de tempo são formuladas pela expressão (8). As restrições (9) restringem que as variáveis de decisão $x_{i j k}$ sejam binárias e as restrições (10) indicam que as variáveis de decisão $s_{i}^{k}$ precisam ser positivas.

\section{CONSIDERAÇÕES FINAIS}

Fazer um roteiro de entregas planejado, avaliando diariamente todos os pedidos pendentes e considerando os critérios que mais impactam nos custos logísticos é o primeiro grande passo para se alcançar uma redução de custos que impacte positivamente os resultados da empresa. O intuito deste artigo foi detalhar o modelo matemático que visa otimizar o problema de roteirização de veículos com janelas de tempo. A implantação da roteirização possibilita a adequação das atividades de modo a reduzir custos sem comprometer o atendimento ao cliente e auxilia na economia da empresa, evitando viagens desnecessárias. Por meio do problema matemático proposto, evidencia-se a relevância da Pesquisa Operacional como ferramenta importante na tomada de decisão dos gestores, com destaque ao método de elaboração de roteiro para minimização dos custos logísticos de distribuição das organizações. Desse modo, compreende-se que a programação linear, 
técnica empregada no modelo, auxilia na minimização de custos e na maximização do lucro da empresa. Logo, a utilização deste método no presente estudo permite inferir a existência de diversas possibilidades de aplicação deste modelo, aqui visto como ferramenta de melhoria no desempenho de uma cadeia de distribuição dentro de uma empresa.

\section{REFERÊNCIAS BIBLIOGRÁFICAS}

[1] CHING, H. Gestão de estoques na cadeia logística integrada: supply chain. São Paulo: Atlas, 2010.

[2] REPOUSSIS, P.P.; Tarantilis, C.D. e Ioannou, G. (2006). The open vehicle routing problem with time windows. Journal of the Operational Research Society, v. 58, p. 113.

[3] RAGO, Sidney F. T. Estratégias para distribuição e transportes (II). Revista Log\&Mam - Logística, Movimentação e Armazenagem de Materiais, ano XXIII, $\mathrm{n}^{0}$ 146, 2002.

[4] BRANDÃO, J. A tabu search algorithm for the open vehicle routing problem. European Journal of Operation Research, v. 157, p. 552-564, 2004.

[5] Hasle, Geir \& Kloster, Oddvar. (2007). Industrial Vehicle Routing. 10.1007/978-3540-68783-2_12. 